\title{
Historiografía latinoamericana de la Primera Guerra Mundial. Los casos de Argentina, México y Colombia
}

\author{
Latin American World War I Historiography: the \\ Cases of Argentina, Mexico and Colombia
}

Renzo Ramírez Bacca ${ }^{1}$

\section{Resumen}

El texto ofrece una revisión crítica sobre la historiografía latinoamericana en torno a la Primera Guerra Mundial. El autor se concentra en los casos de Argentina, México y Colombia para rendir cuenta de las líneas de trabajo, categorías de análisis y aportes recientes sobre la problemática. Tiene en cuenta de igual modo, el contexto historiográfico occidental, pone en discusión y dialoga con los estudios recientes, del mismo modo como advierte sobre sus limitaciones, y el porqué de los vacíos historiográficos señalados.

\section{Palabras clave}

Historiografía, Primera Guerra Mundial, América Latina, Argentina, México, Colombia.

\section{Abstract}

The text provides a critical review of the Latin American historiography during the First World War. The author focuses on Argentina, Mexico and Colombia in order to account for the lines of work, categories of analysis and the recent contributions on the issue. In the same way, it takes into account the Western historiographical context, poses questions and dialogues based on recent studies as well as highlights the limitations and explains the reason for the identified historiographical gaps.

Keywords

Historiography, World War I, Latin America, Argentina, Mexico, Colombia.

Artículo recibido el 25 de agosto de 2014 - aprobado el 30 de octubre de 2014

1 Universidad Nacional de Colombia, Bogotá, Colombia. Correo electrónico: rramirezb@unal.edu.co 


\section{Introducción}

Analizar la historiografía en función del continente latinoamericano como objeto de estudio y la conmemoración de los 100 años de la I Guerra Mundial (en adelante IGM), requiere de un gran esfuerzo y ciertas advertencias preliminares: la primera, el escaso protagonismo latinoamericano durante la Gran Guerra, como también se le conoce a la IGM; la segunda, lo irrelevante que parece ser el acontecimiento en la historiografía latinoamericana; y, la tercera, el contexto histórico en el cual debemos situar y comprender la realidad del continente y de los casos estudiados.

En consecuencia, este texto ofrece un balance crítico sobre la cuestión y una comprensión sobre los enfoques y realidades de la historiografía latinoamericana sobre la IGM. Se advierte, sin embargo, que si bien se ofrecerán rasgos generales, que se inspiran en la historiografía occidental y anglosajona, estos no incluirán los casos de España, Brasil y otros países latinoamericanos, por razones relacionadas con la limitación y disponibilidad de las fuentes y referentes bibliográficos; $y$, se limitará a los casos de Argentina, México y Colombia. Estos se ubican en su debido contexto histórico y se indica por qué no es masiva esa producción -en términos de las dinámicas propias de profesionalización de la disciplina Historia-.

La historiografía es el estudio de la escritura de la historia, de la examinación de sus métodos, y del desarrollo de la ciencia histórica, como de sus formas de conocimiento. Cuando se propone una revisión crítica sobre el decurso de la historiografía latinoamericana en torno a la problemática de la Gran Guerra, es inevitable establecer una selección muy rigurosa y fijar una escala o medida de valor que permita destacar y diferenciar los autores de los distintos enfoques y corrientes. En tal sentido, identificaremos los nuevos temas de investigación, el desarrollo de nuevos conceptos y teorías, y también las innovaciones metodológicas. Si bien, y a modo de advertencia, solo ocasionalmente las dinámicas del progreso científico incluyen al mismo tiempo todos esos elementos (Czamanski y Folmer 2011, p. 493); así como consideraremos conjuntamente y a modo de contexto europeos y americanos que participan de la misma cultura y en definitiva viven problemas paralelos.

\section{Historiografía latinoamericana y occidental reciente: un estado general de la cuestión}

La IGM poco se observa desde la perspectiva latinoamericanista e incluso desde la historia nacional de los distintos países del continente. Es más vista como fenómeno de escala mundial, que se inscribe en la denominada Historia Universal o incluso en la Historia de Europa; y cuya definición como "Guerra Mundial" (Weltkrieg) se debe a los alemanes en 1914, pero cuya etiqueta "Primera Guerra Mundial" fue acuñada en 1945 por los historiadores. Ésta resulta también engañosa, debido a antecedentes, si bien tuvo un alcance global, que afectó al continente americano (Heather, 2014).

Sabemos que las historiografías latinoamericanistas y universales han sido más una construcción de las grandes potencias en cuestión o actores del conflicto bélico, que un apuesta historiográfica de países latinoamericanos. Hay que advertir que en América Latina solo existían las llamadas Academias de Historia, de las cuales las primeras fueron fundadas durante el siglo XIX. Recordemos la creación del Instituto Histórico y Geográfico de Río de Janeiro en 1838, el Instituto Histórico y Geográfico del Río de la Plata en 1854, la Academia Nacional de Historia de Venezuela en 1888, y la Academia Colombiana de Historia en 1902, entre otros casos (Betancourt, 2008 p. 46; Ramírez, 2008a, p. 154). Que ante todo representan un impacto del historicismo germano en el continente (Ramírez, 2008b). Finalizando la IGM surge la primera revista especializada en historia: Hispanic American Historical Review en 1918. En Estados Unidos, Lewis Hanke trabaja en especial el periodo colonial de la América española y también coordina el Handbook of Latin American Studies, el primer instrumento bibliográfico conocido en Norteamérica, que aparece en 1936. Para no mencionar las dinámicas institucionales de profesionalización 
de la Historia, que en el caso colombiano lo observamos tan solo a partir de la década 1960 (Ramírez, 2011b). Así, entre 1945-1975, se diferencian los elementos historia/ciencia, historia/técnica y la historia/profesión. Se crean nuevas condiciones en los historiadores, pero también una dependencia. Es la subordinación profesional del historiador hacia las instituciones académicas, docentes y del Estado, lo cual contribuye a acentuar la importancia de la técnica y atenuar el horizonte apolítico dentro del cual el historiador actúa y a veces se define. Estas condiciones incidieron en el modo de pensar sobre el pasado (Bagú, 1996, p. 56). Ese es el escenario y respaldo institucional de los historiadores frente a ciertas interpretaciones. Es allí donde encontramos la razón de la brecha o vacío historiográfico, que pretende señalarse en este año 2014, que de igual modo, no excluye a los mismos europeos, como se verá más adelante.

La celebración de aniversarios en torno a acontecimientos de importancia global o continental siempre ha sido un buen motivo de inspiración para los historiadores en las últimas décadas. En nuestro caso la conmemoración de los 100 años del estallido de la Gran Guerra, ha servido para que países como Argentina ${ }^{2}$, México, ${ }^{3} \mathrm{Chile}^{4}$ y Colombia, ${ }^{5}$ entre otros; además de centros de estudios latinoamericanos europeos se destaquen por la organización de eventos académicos, exposiciones y documentos de tra-

2 En Argentina, el Instituto Provincial de Estadística y Censos (Ipec), publicó un informe sobre las consecuencias de la IGM en dicho país, en especial las demográficas, migracionales, sociales y económicas. Cf. Ipec - Provincia de Santa Fe (2014).

3 En México se organizó el Coloquio Internacional América Latina y la Primera Guerra Mundial. Una Historia Conectada entre el 26 y 27 de junio de 2014, el cual contó con el apoyo del Consejo Nacional para la Cultura y las Artes (Conaculta), entre otras instituciones. Cf. México, Consejo Nacional para la Cultura y las Artes (Conaculta, 2014).

4 La agenda cultural del Instituto Francés en Santiago de Chile en 2014 contempla ciclos de conferencias y cine destacando de modo particular el papel de las mujeres durante la Gran Guerra.

5 La muestra es el Congreso Internacional América Latina y los 100 años del comienzo de la Primera Guerra Mundial, realizado entre el 11 y 15 de agosto de 2014, y con el respaldo de las siguientes instituciones: Universidad Nacional de Colombia, Universidad Autónoma de Colombia, Fundación Gilberto Álzate Avendaño, Academia Colombiana de Historia y la Asociación Colombiana de Historiadores. bajo $^{6}$. Además, han tenido eco los grandes medios de comunicación escrita y hablada de los continentes, con retratos iconográficos y pinceladas enciclopedistas, que referencian este fenómeno histórico, y que, a propósito de la reciente crisis diplomática en Ucrania, es retomando como un elemento de inflexión histórica por parte de líderes políticos alemanes ${ }^{7}$. Así, este año hemos vivido una oleada de ensayos, novelas, debates, cómics, presentaciones multimedia y hasta juegos, que intentan explicar las causas, el desarrollo y las consecuencias de una convulsión que cambió el curso de la historia ${ }^{8}$.

Según Stefan Rinke (2014), quien reconoce que América Latina desempeña, en términos de análisis histórico, un papel bastante secundario a la hora de estudiar y comprender la Gran Guerra.

La interconexión entre los eventos globales y los desarrollos locales durante la Primera Guerra casi ha pasado desapercibida. Los libros y los tratamientos de la historia de América Latina usualmente toman la Gran Depresión como punto de partida para las periodizaciones. De acuerdo con este punto de vista, la Gran Depresión fue el momento cuando América Latina tomó un nuevo rumbo. La Primera Guerra Mundial, sin embargo, no desempeñó ese papel central como ruptura en el desarrollo del continente. En los libros sobre la Primera Guerra Mundial -incluso en los más conocidos- América Latina casi nunca es mencionada. (Cf. Zuñiga, 2014).

6 En Alemania el Instituto Ibero-Americano (Berlín), el GIGA Institute of Latin American Studies (Hamburgo) y la Editorial Iberoamericana/ Vervuert (Frankfurt am Main/Madrid) y su órgano difusor Iberoamericana, prepararon un dossier sobre la Primera Guerra Mundial y América Latina editado en el Vol. 14, núm. 53 (2014). Cf. http://journals.iai.spk-berlin.de/index.php/iberoamericana/issue/view/6.

7 Los diarios europeos El País (España), Le Monde (Francia), La Stampa (Italia), Gazeta Wyborzca (Polonia), SüddeustcheZeitung (Alemania) y The Guardian (Reino Unido) han reseñado el centenario del conflicto mundial en el cual muestran las consecuencias bélicas en la actualidad. Del mismo modo, como los principales diarios de países latinoamericanos.

8 Babelia (2014), la revista cultural de El País, recomienda veinte artículos que aportan las claves del conflicto. Cf. "20 artículos para entender la Primera Guerra Mundial", El País. Babelia, 4 de junio de 2014, http://cultura.elpais.com/cultura/2014/06/04/babelia/1401871263_984726.html 
El mismo Rinke (2014, p. 87), reconoce que la IGM desató mucha discusión sobre su significado para los países y la región en general, sin embargo esto no se refleja en la historiografía latinoamericana ${ }^{9}$. Los años de la Gran Guerra casi nunca son discutidos como un marco de tiempo en sí mismo $y$ en la multitud de libros sobre la IGM en general -incluso en los más conocidos y en los que recientemente se conocen como global histories- América Latina casi nunca es mencionada.

Phillip Dehne (2014), apoyándose en Percy Alvin Martin (1925), dice que es una deuda de los historiadores latinoamericanos, sin desconocer que los primeros historiadores enfatizaron en la historia diplomática y las relaciones internacionales desde la perspectiva de sus respectivos países, pero sobre todo en la política de neutralidad. Posteriormente, el interés se centró en las transformaciones económicas de los países latinoamericanos, como consecuencia de la guerra. $Y$, advirtiendo el interés reciente por los aspectos político-culturales y sociales y la participación de intelectuales, inmigrantes, y la prensa. Ello para señalar, a pesar de la escasa literatura, cómo el análisis sobre el "efecto de la guerra" en los países del continente es la perspectiva sobresaliente.

Lo anterior indica que en nuestra actual sociedad poco o nada sabemos de esta "guerra mundial". Es una realidad que afecta de igual modo a las nuevas generaciones de los países que participaron directamente en el conflicto. Un estudio reciente demuestra que en Gran Bretaña, de un total 2000 jóvenes (entre los 18 y 35 años de edad) encuestados sobre su conocimiento de las principales guerras $\mathrm{y}$ campañas militares del siglo XX, 17 \% admitió que

9 El investigador se opone a la hipótesis general de que la Gran Guerra representó la ruptura para que América Latina tomara un nuevo giro, y se apoya en la realidad específica de cada país. Señala que, en el caso de México y Argentina, el año 1910 es usualmente visto como una bifurcación de caminos. En México debido al inicio de la Revolución; en Argentina, como consecuencia de los cambios políticos y las movilizaciones sociales que afloraron en el transcurso del centenario de la Independencia. Esto también es cierto para Perú en 1912, mientras que en Nicaragua o Panamá los cambios importantes en la relación de dichas naciones con Estados Unidos fueron vistos como hitos en 1912 y 1914. Para países tan diversos como Bolivia, Chile, Perú y Guatemala, los años 1919 y 1920 fueron aceptados como importantes fechas de transformación social (cf. Rinke, 2014, p. 87). nunca había escuchado hablar de la IGM; y $25 \%$ no sabía que el conflicto se desarrolló entre 1914 y 1918 (Rudavičius, 2014). En Alemania, por ejemplo, no hay claridad sobre quiénes propiciaron el inicio de la guerra. En Francia consideran que hay muchos aspectos y enfoques por revisar. En Inglaterra, el ministro de Educación, Michael Gove, ha recibido críticas por su fallida intención de reescribir el currículum de historia y demorar la enseñanza de todo lo ocurrido después del 1707 -incluidas las dos guerras mundiales- al segundo ciclo y a partir de los once años $^{10}$. En Rusia hay un desprecio por una guerra que es considerada "imperialista", allí se explica que fue otro régimen el que decidió participar, en un cruce de alianzas difícil de entender entonces y ahora, pero en un contexto de revisionismo histórico teniendo en cuenta la desaparición de la Unión Soviética. Lo que queda en la memoria es que la IGM fue un fracaso y una vergüenza para el país, la cual fue estudiada prácticamente en el contexto de la Revolución bolchevique. En Italia, la Gran Guerra se ve como el antecedente inmediato al surgimiento del fascismo y la llegada de Benito Mussolini al poder, pero también un paso fundamental para la construcción del actual país e identidad europea. En Turquía se enaltecen las grandes batallas como la de Galípoli, o batalla de los Dardanelos, ignorando el genocidio causado al pueblo cristiano armenio en manos del Imperio otomano; advirtiendo que la guerra no es conmemorada; pero cada 18 de marzo se celebra el Día de la Victoria y de los Mártires. En Estados Unidos, la visión sobre el papel de los países no es la mejor, pero se comparte la idea que todos los actores deben asumir culpa por una catástrofe que nadie quería. La conmemoración se maneja con discreción, aunque una comisión de historiadores y militares está preparando más eventos para 2017: el aniversario de la entrada de Estados Unidos en la guerra. En Bélgica - un país neutral- la IGM solo se estudia a grandes rasgos, una mirada a los ganadores y perdedores, y cuáles fueron los desencadenantes

10 La Asociación de Historiadores y la mayoría de los profesores boicotearon los planes de Gove, quien se vio forzado a reescribir el programa de historia en el año crítico del centenario de la Gran Guerra. 
de la guerra. Este abordaje también permite explicar el ascenso de los totalitarismos en Europa y su desenlace en la Segunda Guerra Mundial, donde Bélgica tiene una incidencia más notable (Sánchez et al., 2014).

\section{Miradas globales}

Norbert Lammert, presidente del Bundestag alemán, señaló recientemente: "Entendimos, aunque demasiado tarde, que el camino militar no es el adecuado para lograr transformaciones y que solo puede ser un último recurso en casos extremos", al tiempo que el ensayista franco-alemán Alfred Grosser recordó que historiadores alemanes y franceses habían llegado a la conclusión, en un congreso celebrado en 1952, que todos los países que participaron en el conflicto tuvieron parte de responsabilidad (Agencia EFE, 2014).

Pierre Purseigle y Jenny Macleod (2005, p. 7) advierten que desde 1954 se han identificado -a juzgar por las referencias evidenciadas en la reconocida base de datos Historical Abstracts- 2000 revistas que han publicado sobre el periodo y el área geográfica. En tal sentido, 619.002 libros y artículos pueden sumarse, de los cuales 6860 son referencias explicitas sobre la IGM. Doscientos libros y artículos fueron publicados entre 1980 y 1999. Las referencias señalan que esta producción representa entre el 1 y $1,5 \%$ de la producción histórica global. También es posible que el aumento de la producción académica se deba a los aniversarios conmemorativos de la guerra. Hay que señalar que la mayor parte de la producción se ha hecho en inglés, seguido del francés, alemán, italiano y ruso desde 1954. En la anterior cifra no se incluye al producción académica en español, e incluso algo del American Bibliographical Center (ABC), registrado solo desde 1964, y la serie bibliográfica, America: History and Life, que comienza a ser de libre acceso en la web a partir de 1998 (cf. ABC-Clio, s.f.). Además, cuando se leen textos recientes, como el editado por John Horne (2012), los países latinoamericanos no existen, excepto para señalar que las potencias $A B C$ de Suramérica -Argentina, Brasil y Chile-, ordenaron la compra de acorazados antes de la IGM, a modo de contexto o antecedentes de las acciones navales desarrolladas durante el conflicto.

De igual modo, así como se advierte que se trata de un conflicto transnacional, hay un gran vacío en cuanto a estudios comparados sobre la guerra, no obstante la importancia del programa de historia comparada propuesta por Marc Bloch, un veterano de la IGM. Las razones tienen que ver con las falencias lingüísticas y culturales de los historiadores europeos. En contraposición prevalece una mirada nacionalista y etnocentrista. En tal sentido parece que las orillas más claras en la corriente historiográfica sobre la guerra la representan la historia militar y la historia cultural. De esta última orilla ha resultado una perspectiva interdisciplinaria que se deriva, como lo señalan Pierre Purseigle y Jenny Macleod (2005, pp. 9, 14), de la "nueva historia cultural" de la IGM, también conocida como la "historia del consentimiento -history of consent-, sin desconocer que en los diversos enfoques incluimos a la historia social -history of defiance-, y también una historiografía marxista sobre la guerra. Un buen ejemplo es el texto Evidence, History, and the Great War: Historians and the Impact of 1914-18, editado por Gail Braybon (2003), donde diversos autores abordan la guerra a partir del papel de la mujer, las fotografías, la alimentación, las mentalidades, entre otros temas, pero desde los casos de Francia, Alemania, Gran Bretaña, Rusia e Italia. Si bien, dos años más tarde, Theo D’haen, Paul Giles, Djelal Kadir y Louis Parkinzon Zamora (2005) ofrecen una compilación con distintas líneas donde resaltan aspectos religiosos, étnico-culturales, transnacionales, literarios, identitarios, simbólicos, entre otros. Así, como también la edición de Santanu Das (2011), Race, empire and First World War writing, de cierto modo, se centra en la categoría de raza, para estudiar toda esa multiplicidad de soldados provenientes de distintas colonias de los países que participaron en la guerra, y que son objeto de atención: chinos, vietnamitas, hindúes, senegaleses, neozelandeses, jamaiquinos; en fin africanos y asiáticos, mas no latinoamericanos. 
La era de los datos tiranos, que comienza en agosto de 1914, sin duda obliga a los estados a caracterizarse: a) en una esfera económica que representó su tendencia a tener el control de los medios de producción, distribución e intercambio; al tiempo que se da una apelación de los gobiernos a las organizaciones obreras con el fin de lograr ciertos mecanismos de control, que significan por lo tanto sindicalismo y corporativismo, o sea étatisme; b) en la esfera intelectual, con una represión por parte los estados contra cualquier tipo de opinión que fuera desfavorable al interés nacional, y c) que Purseigle y Macleod (2005, pp. 31-32) advierten en la "organización del entusiasmo”. En cualquier caso, una buena mirada y comprensión de lo que fue la guerra en distintas dimensiones y desde la perspectiva de la crisis generada es bien lograda por Pierre Renouvin (1999). En lo que sigue, se reduce el referente europeo y anglosajón para hacer una aproximación a los países latinoamericanos.

\section{Caso argentino}

La Argentina de comienzos de siglo XX tiene una clara relación con el mundo occidental. Sus dirigentes admiraban y trataban de imitar de Francia su cultura, de Inglaterra el desarrollo económico, y de Alemania su militarismo. Era epicentro de un fenómeno de migración internacional sin precedentes. La población en las principales ciudades, que en 1896 era de 951.440 habitantes, pasó a 2’340.642 habitantes en 1914, con epicentro en el Gran Buenos Aires ${ }^{11}$. El país vivía la tasa más alta de crecimiento de toda su historia demográfica. En 1914 se realiza el Tercer Censo Nacional de Población, arrojando un total de 7'885.237 habitantes, de los cuales 2'357.952 (30 \%) eran extranjeros en su mayoría españoles e italianos (SEPA, s.f.). También la Generación del Centenario (1816-1916) se preparaba para celebrar el Grito de Independencia con España, que ante todo fue una expresión cultural en medio del furor industrial y comercial del país. Declarada la Gran Guerra -como se le conoció en el país gaucho- el

11 La población total hacia 1895 era de 4'044.911, y en 1914, de 7'903.662 (Demografía en Argentina, s.f.). gobierno adopta la política de neutralidad, que le daría muchos réditos en la diplomacia internacional.

Ese escenario es abordado en su debida dimensión histórica y social por Ramón Tarruella (2014), pero limitándose al contexto de la IGM. Las preguntas en torno a cuál era la Argentina de la época, cómo se fue defiendo su política de neutralidad, y también cuál fue el escenario de llegada de Estados Unidos para ocupar los espacios británicos y alemanes. En cualquier caso las líneas de gruesas de aproximación al conflicto se han dado desde una perspectiva propia a la historia económica y la historia diplomática.

El factor económico es importante en la historiografía argentina. Resalta el análisis sobre el impacto de la guerra en el desarrollo de la industrialización sustitutiva. Recordemos que la dependencia de este país con la Gran Bretaña antes de la guerra era la nota relevante de la economía, si bien era evidente cierta incursión de capitales norteamericanos, poco antes de iniciarse la guerra. El papel del Estado comienza a cambiar por las dinámicas del conflicto bélico y, por lo tanto, también se ha examinado la política fiscal y presupuestaria debatida en el Congreso argentino y la estrategia asumida durante la guerra, incluso las realizadas posteriormente pero ya con una perspectiva comparativa con países como Brasil, Chile y Perú. En síntesis, los enfoques y análisis económicos siempre tendrán relación en torno a cómo se desencadena un nuevo proceso económico nacional partiendo de la hegemonía británica en la región, la accedente influencia comercial germana y el avance de los intereses norteamericanos. Lo anterior tiene un trasfondo histórico relacionado con el papel económico que jugará Argentina a escala global en las décadas posteriores. Hacía 1913 las exportaciones de Argentina representaban el 30 $\%$ del total de América Latina; y para el mismo año Gran Bretaña era el principal abastecedor de Argentina, Bolivia, Chile y Perú. Así, como Francia lo era para el Ecuador, Haití y Venezuela. Y, Alemania para Guatemala, Paraguay y Uruguay. Así, Ricardo Weinmann (1994) se concentra en el caso argentino para analizar un tema central de interés: su línea 
diplomática de neutralidad, la transición política y el continuismo económico durante la guerra.

Hay que señalar entonces otra línea de trabajo relacionada con el papel de la diplomacia argentina. A nivel latinoamericano hasta la IGM, se dieron por lo menos tres tendencias. La primera es una corriente a favor de la unidad con EE.UU., en la que se incluyen algunos países como Brasil. La segunda es la de una oposición abierta y directa, como es el caso de Argentina. Y la tercera, de acuerdo con Glinkin (1984, p. 51), una oposición en voz baja, la cual no siempre apoyaba decisiones en favor del sistema de unidad panamericano como es el caso de Bolivia, Paraguay y Perú, entre otros. Durante la IGM Argentina se destacó por su posición de neutralidad. No es extraño entonces el interés de historiadores argentinos por el estudio de la diplomacia argentina, su participación y vínculos con las naciones participantes en el conflicto, no obstante los incidentes diplomáticos, pero sobre todo porque la política de neutralidad, de igual modo, es similar en la mayoría de los países de continente. Un ejemplo, es el texto de Raimundo Siepe (1992), el cual se centra en el gobierno de Hipólito Yrigoyen (1916-1922, 19281930), para analizar las relaciones económicas de su administración durante la Gran Guerra y además porque considera que la línea de neutralidad argentina se basó en principios pacifistas, de fraternidad y cooperación mundial, aunados con accionar humanitario y transparente, que el presidente defendió en la Sociedad de Naciones en la posguerra (cf. de Monserrat Llairó y Siepe, 2005). Fue un principio que abrió carrera en las concepciones diplomáticas, especialmente en materia de paz, justicia y libertad, y permitió que la neutralidad argentina contribuyera al derecho internacional y el humanistarismo (humaniatiarism) (cf. Siepe, 1992; Den Hertog y Kruizinga, 2011). Se trata de analizar el contexto y los intereses de los partidarios de la línea de neutralidad diplomática y los partidarios de la ruptura de las relaciones con Alemania a la luz del papel que desempeñó la prensa de la época. Es decir, lo que en el ámbito local se conoció como el debate entre rupturistas y neutralistas.
En concreto, lo más reciente, en términos historiográficos, resultan ser estudios sobre historia social e historia cultural. El papel de los medios de comunicación, particularmente la prensa, es objeto de atención. Los distintos países, en mayor o menor escala, vivieron cierta polarización a través de la opinión pública en favor o en contra de la guerra, en otras palabras en favor o en contra de alemanes, británicos o norteamericanos, y los beneficios o contradicciones de la política de neutralidad en el conflicto. Sin embargo, compartiendo con María Inés Tato (2014), en la historiografía nacional latinoamericana, son escasos los aportes en tal sentido.

La prensa y el papel de ciertos intelectuales, generadores de opinión pública, son también objeto de atención en torno a las posiciones relacionadas con la política diplomática de neutralidad, la tendencia de ruptura de relaciones con Alemania, y algunos aspectos relacionados con la identidad nacional y su relación con Europa. Hay que resaltar que por el contexto histórico migracional de la época -la mitad de la población bonaerense era inmigrantes de primera generación- existe un potencial de fuentes que permite evaluar el comportamiento de las diversas comunidades, por ejemplo, las de ascendencia francesa, alemana, judía, italiana y británica, y su relación con sus países de origen y la nación argentina. Aspectos de movilización o protesta social, evidenciados en especial a partir de 1917, también son tenidos en cuenta. Como concluye Tato (2012, p. 96), esa historia social y cultural de la guerra está enfocada en el análisis de "[...] las redes de sociabilidad, el asociacionismo, las representaciones ideológicas de los actores sociales y políticos, la discursividad, las representaciones ideológicas y las identidades"12.

En la misma línea cultural Tato (2012, pp. 205213) aborda a los intelectuales germanológicos argentinos, en medio de un escenario en el que, como se sabe, el país se encontraba dividido entre germanológicos y aliadófilos. Intelectuales que eran guías y orientadores de la opinión pública, que según la autora se afiliaron a modelos culturales

12 En total, son cerca de cincuenta títulos los trabajos que se pueden considerar como aporte al tema desde la historiografía argentina. 
que habían adquirido en su formación profesional y que se expresaron en especial en la revista Nosotros durante 1915, advirtiendo que la mayoría simpatizaba con los aliados. En todo caso concluye que la Gran Guerra provocó agudas tensiones culturales en el seno de las élites argentinas, en torno al modelo francés, hegemónico desde la segunda mitad del siglo XIX, y del alemán, de circulación más restringido; pero cuyo consenso era la neutralidad durante el conflicto, y por ende a la Argentina le correspondía adoptar una política fundada en la neutralidad.

Tato (2011) también analiza el llamado a la patria por parte de los británicos e italianos residentes en la Argentina. Y, de igual manera la disputa que gira en torno a la denominada argentinidad, que en esencia se trata de un altercado entre o al interior de los miembros de las distintas comunidades de emigrantes de primera generación respecto de su postura y participación en la guerra; quienes finalmente fueron etiquetados como rupturistas y neutralistas.

Hernán Otero (2011), de igual modo, se ocupa de la comunidad francesa en Argentina, su respuesta y división frente la movilidad militar causada por la guerra y las tensiones que surgen de la doble pertenencia legal y cultural de los emigrantes y sus hijos. En todo caso advierte que ese acatamiento de la movilización de la primera generación esgrime diversas hipótesis en la historiografía sobre el tema. Una de ellas es de carácter cultural y en particular el grande nacionalismo en la masa migratoria, que se advierte cuando se le compara con el caso de británicos, italianos y alemanes, especialmente. La segunda hipótesis se relaciona con las medidas de presión implementadas para favorecer la movilización y que son de naturaleza política e institucional. La cuarta tiene que ver con el núcleo étnico de la comunidad y su lugar de origen, y las presiones consulares en las zonas donde ellos provenían (en especial Buenos Aires y Rosario). Por último, señala Otero, se destaca la hipótesis de la intensidad de la integración de los grupos migratorios: "[...] la alta integración de los hijos de franceses e italianos a través de la poderosa maquinaria de nacionalización de la escuela pública argentina, explica la casi nula respuesta de la segunda generación en ambos casos".
Se revisará a continuación otro caso que resulta interesante, dentro de su debido contexto histórico, y relación con Estados Unidos y Europa.

\section{Caso mexicano}

En México, por distintos conflictos como la intervención estadounidense (1846-1848), la Segunda Intervención Francesa (1862-1867), y el proyecto de educación liberal durante la segunda mitad del siglo XIX, con el tiempo se fortaleció un proyecto de cierta unidad e identidad nacional, que en la coyuntura de la IGM, también permitió consolidar la llamada Revolución mexicana (1910-1917) ${ }^{13}$ y con ello, como lo señala Lorenzo Meyer (2014), "poner fin a una tiranía, instaurar la democracia, restituir la tierra al campesino, dar derechos a los trabajadores y devolver 'México a los mexicanos', y en especial su Constitución de 1917 [del 31 de enero], que es un proyecto realmente revolucionario, anterior a la Revolución bolchevique [ 25 de octubre/7 de noviembre]. Puede advertirse que la IGM y su propia dinámica militar y económica, no permitió la inferencia de las potencias en México, cuya revolución tenía rasgos antiimperialistas y anticapitalistas.

El papel de México es de especial interés para los historiadores debido a su cercanía con Estados Unidos, país que ingresó en abril de 1917 en el conflicto. "México se convirtió en un territorio de guerra entre espías alemanes, norteamericanos, ingleses y franceses que desde ahí trataban de debilitar a su enemigo" (Usi, 2014). Alemania propuso a México, a través de un telegrama secreto (telegrama Zimmerman), que los británicos descifraron, que declarara la guerra a Estados Unidos. A cambio le ofrecía una compensación económica y la devolución de los territorios perdidos ante su vecino del norte. El entonces presidente, Venustiano Carranza, contestó educadamente que no estaba interesado porque el plan no tenía pies ni cabeza. Rinke señala:

13 La Revolución mexicana es el movimiento armado iniciado en 1910 para terminar la dictadura de Porfirio Díaz y que culminó oficialmente con la promulgación de la nueva Constitución Política de los Estados Unidos Mexicanos de 1917 (cf. Presidencia de la República de México, 2013). 
Carranza aprovechó el conflicto entre Estados Unidos y Alemania para proclamar su célebre Constitución de 1917. [Él] sabía que el momento era muy oportuno porque Estados Unidos tenía otras cosas más importantes que hacer que luchar contra esa Constitución que era revolucionaria, un hito mundial, por la nacionalización de los recursos naturales y la introducción de la primera legislación social de las Américas. (Usi, 2014).

Es posible hacer muchas preguntas relacionadas con la Revolución mexicana y la Gran Guerra, lo cual también permite comprender el interés, en torno a la problemática, en el país azteca durante este año (2014). Eventos académicos plantean diversas líneas de discusión como: 1) el interés de la prensa mexicana por el conflicto, alimentado y financiado por servicios de propaganda europeos; 2) la manera como la guerra se constituyó en un argumento para terminar ciertos debates que agitaban el mundo político revolucionario mexicano, en una escala más amplia;3) cómo la guerra permitido la redefinición identitaria de algunos países latinoamericanos, como por ejemplo en el caso argentino; 4) el impacto económico de la guerra sobre las poblaciones latinas; 5) el impacto de la guerra en la cultura de la guerra y la cultura popular en América Latina.14

Pero también están las investigaciones que se centran en la línea de historia económica. Recientemente Sandra Kuntz Ficker (2014) publicó un texto sobre las consecuencias de la Gran Guerra en el comercio exterior mexicano y su causa; en la dicotomía de la IGM y la Revolución mexicana, que es vista también como una guerra civil. La autora considera

14 En México, la Dirección General de Bibliotecas del Consejo Nacional para la Cultura y las Artes (Conaculta), junto con otras instituciones organizaron el Coloquio Internacional América Latina y la Primera Guerra Mundial. Una Historia Conectada, entre el 26 y 27 de junio de 2014. Entre los historiadores mexicanos participaron Javier Garciadiego, Sandra Kuntz y Lorenzo Meyer, de El Colegio de México; Leonor Ludlow y Álvaro Matute, del Instituto de Investigaciones Históricas de la Universidad Nacional Autónoma de México; Jean Meyer, del Centro de Investigación y Docencia Económicas (CIDE); Mario Cerutti, de la Universidad de Nuevo León, y Javier Pérez Siller, de la Benemérita Universidad Autónoma de Puebla. Además, de contar con Pierre Purseigle de la Universidad de Yale y Olivier Compagnon, de la Universidad Sorbonne Nouvelle de París. En total cerca de 23 historiadores de Francia, Inglaterra, Alemania, Portugal, Argentina, Cuba, Perú y Estados Unidos participaron en distintas mesas y conferencias. que de una parte se reduce el comercio con los países europeos, como consecuencia de la guerra, lo que posibilita un aumento de las relaciones comerciales con Argentina. Pero de otra, se da un aumento del intercambio con Estados Unidos, este último como resultado de la guerra civil mexicana15.

John Womack (1987), al igual que Kuntz Ficker, le interesa el tema. También está Esperanza Durán $(1981,1985)$, quien analiza la relación con las potencias y aborda el papel del petróleo mexicano, y Friedrich Katz (1984), que de igual modo estudia y relaciona los casos a partir de la revolución mexicana y la guerra europea. El interés por lo económico se debe a que existen ciertas fuentes estadísticas confiables de los estados en cuestión para arrojar ciertas hipótesis. Lo cierto es que en vez de darse una posible reducción en la balanza comercial, el intercambio aumentó ligeramente, por los efectos mismos de la guerra -la demanda de insumos de las potencias centrales- y el creciente papel de Estados Unidos como socio comercial, en varios países latinoamericanos. Lo que no sucedió con las importaciones, que se redujeron de manera severa con los países europeos y también con Estados Unidos durante el primer año. Esta situación hay que ponerla en contexto, teniendo en cuenta las estrategias de la guerra en especial entre Gran Bretaña y Alemania, como el bloque naval comercial y ataque con submarinos a flotas mercantes, las que en realidad causaron miles de muertes por la pérdida de millones de toneladas de alimentos (Kuntz, 2014, p. 127).

Antes de cerrar este caso, es necesario advertir sobre el interés de los colegas mexicanos, acerca del papel de la prensa de ese país durante la guerra. Yolanda de la Parra (1986), por ejemplo, identifica tendencias políticas y posiciones en favor de las potencias, especialmente Estados Unidos y Alema-

15 Kuntz Ficker evidencia cómo el principal socio en las exportaciones antes de la guerra era Estados Unidos, si bien en 1914 el valor de las mismas comienza disminuir. Los productos principales eran, en orden de importancia: petróleo crudo, cobre en barras, café y algodón en 1913. En el año siguiente cuando se reduce el tráfico son: petróleo, caña de azúcar, plomo de barras y café. Es válido advertir que para los dos años no hay cifras sobre el comercio del oro, y que este metal, junto con el cobre y el petróleo, representaban el $90 \%$ del intercambio (cf. Kuntz, 2014, pp. 122, 124). 
nia. Posiciones vistas también como un reflejo de la manipulación de la opinión pública, ya para actividades propagandísticas, financiamiento, espionaje y presiones comerciales por parte de las potencias.

\section{Caso colombiano}

En Colombia, durante la administración del presidente José Vicente Concha (1914-1918), la crisis económica y la carencia de políticas adecuadas para su solución generó la protesta social y corporativa. La paz social anhelada por la sociedad se deterioró. Esa paz que se logró como resultado de la Guerra de los Mil Días (1899-1903). Asimismo, con la muerte de Rafael Uribe Uribe el liberalismo cae en el sectarismo y la desorganización. La realidad es que la violencia se acentuó y reapareció en el conflicto bipartidista. En ese nuevo enfrentamiento se inicia una nueva ola de violencia política en las regiones, especialmente en los Llanos Orientales, Huila, Santander, Valle, Tolima, Cauca y la costa Atlántica. En esta última región eran protagonistas la United Fruit Company con los productores y cultivadores de banano.

Colombia, al igual que otros países de la región -Argentina, México, Chile, Paraguay, Salvador, Venezuela y España-, optó por una política de neutralidad frente a las potencias en conflicto: la Triple Alianza, formada por las potencias centrales: el Imperio alemán y Austria-Hungría, y la Triple Entente, formada por el Reino Unido, Francia y el Imperio ruso, a la cual se uniría Italia. En el país existían intereses alemanes que el gobierno consideraba necesario custodiar. Los alemanes en la zona del Darién tenían también una plantación de banano y hacían transacciones con los bancos colombianos. Esta política inquietaba a los países partícipes en la guerra. El gobierno es presionado por medios diplomáticos para ofrecer explicaciones sobre su alineamiento en favor de Alemania. Las dos únicas estaciones de radio existentes en el país -una de norteamericanos y otra de alemanes- fueron el pretexto. La estación alemana fue intervenida por el Estado, pero su supuesta continuidad de emisiones fue el pretexto para que el gobierno británico presionara y se hiciera visible la intervención de un tercero, el gobierno estadounidense. No obstante, la política de neutralidad se mantuvo, si bien el país no cumplía ningún papel importante para ninguna de las potencias. La presión en todo caso se hizo por medios de los importadores y consumidores de café con lazos en Estados Unidos, recordando que este país era el principal consumidor del grano colombiano. Esta relación económica no podía perderse, al igual que los intereses de firmas norteamericanas en la explotación de petróleo, lo cual se podía ver como una manera de resolver la crisis económica nacional.

No obstante, la política de neutralidad frente a las potencias en conflicto adquirió diversos matices. Los alemanes con dos periódicos -Germania y Transoceam-, resaltaban en Bogotá la política de agresión de los aliados. Por razones relacionadas a la pérdida del Istmo panameño, el pueblo colombiano cultivaba un sentimiento antinorteamericano, por lo cual las noticias que llegaban del Viejo Continente sobre la ofensiva alemana eran vistas con simpatía por la gente. Pero también existía el otro bando, favorable a la posición británica y relacionada con Norteamérica, que eran ante todo las élites económicas del país. Antioquia pareció la zona en donde los aliados contaban con una opinión más favorable, quizás por las dinámicas del capitalismo, la industrialización fabril y las exportaciones de café. De otra parte en el clero también había opiniones divididas.

Antonio Rodríguez (1985) recuerda que la prensa extranjera, especialmente de las potencias, distorsionaban la situación del país, por lo cual el cuerpo diplomático se vio obligado a hacer rectificaciones. Todo esto con la intención de romper con la política de neutralidad del gobierno colombiano y provocarlo a fijar una posición en el conflicto. En realidad Colombia no se guiaba en materia de neutralidad por las conferencias de La Haya (1899 y 1907). El hecho de considerarse nuevas doctrinas tampoco significaba fijar una censura. El cuerpo diplomático se ponía en contexto a partir del caso brasileño y la posición británica respecto de su política de neutralidad, vista como nuevas y fases recientes del progreso internacional. La prensa bogotana 
defendió la posición del gobierno, que recogía el sentimiento antinorteamericano de gran parte de la población colombiana. La presión se hizo mayor cuando Estados Unidos decide participar en la guerra. La utilización de tecnología bélica durante la guerra y en el territorio colombiano fue vista como causal de perjuicio norteamericano en el territorio nacional. Pero, ¿qué se tiene desde la historiografía colombiana sobre esta problemática?

La creación de la Academia Colombiana de Historia, en 1902, tendría relación con la necesidad de lograr cierta identidad de lo nacional respecto de su territorio, lo cual es quizás una consecuencia de la secesión de Panamá, circunstancia anterior a la Gran Guerra. A comienzos de siglo los problemas fiscales no permitieron que se hicieran reformas modernizantes en el campo de la educación. Los proyectos se orientaron a fortalecer la idea de las identidades regionales y un Estado centralizado. Había una necesidad de dar cumplimiento a lo ordenado por la Constitución Nacional, pero la instrucción nacional no andaba con celeridad al igual que en otros sectores. Por la falta de recursos no se podía impulsar. En los estudios superiores también había la intención de mejorar el régimen de las facultades de Matemáticas, Ciencias Naturales y Medicina, donde se introdujeron reformas. También se gestionaron servicios de profesores extranjeros - que eran indispensables-, pero no se podía realizar por el estado mismo de la guerra. Incluso, con la profesionalización de la disciplina en el medio colombiano, en la segunda mitad del siglo XX, de igual modo, poco o nada novedoso se puede resaltar en cuanto a la historiografía colombiana con énfasis en América Latina. Los estudios de historia política, cultural, local y regional son los que tienen mayor eco, sin desconocer otras tendencias de la historiografía reciente, pero nada que estimule la comparación con otros países de la región o incluso del papel del país en la arena internacional (cf. Ramírez, 2008a; 2011a; 2011b; Ramírez y Ospina, 2011). La excepción la constituye el reciente esfuerzo de diversas instituciones con el Congreso Internacional: América Latina y los 100 del comienzo de la Primera Guerra Mundial, donde se lograron ventilar diversos temas relacionados con el marco temporal de la guerra y el contexto nacional e internacional, pero en especial sobre aspectos culturales -música, género, religión, educación, cine y literatura-, económicos e historiográficos, además de contar con invitados nacionales e internacionales que trataron la problemática desde las experiencias de otros países como Cuba, Rusia, Italia, Venezuela y Brasil ${ }^{16}$.

En fin, poco o nada son los aportes de nuestros académicos en aquellos tiempos y los recientes. De tal manera que, cuando se revisa ese componente historiográfico, no se encuentran reales escuelas o instituciones, historiadores o intelectuales respetables conocedores del tema y con visión universal. Se sabe incluso que la élite política colombiana en esos años no estaba bien informada sobre lo que estaba sucediendo en Europa. Pero no hay duda de que existen vetas interesantes para tratar como el papel de la prensa colombiana y las relaciones diplomáticas del país con respecto al conflicto, pero en especial sobre los intereses comerciales germanos y norteamericanos en el país. Y, que el reciente Congreso Internacional posibilitará una mejor comprensión del contexto sociohistórico, cultural y económico colombiano cuando se publiquen sus memorias.

En realidad, la visión provincial o regionalista poco permite mirar ese papel de lo externo en las dinámicas internas. Ese parroquialismo y regionalismo ha creado finalmente cierto aislamiento e incomprensión de los investigadores foráneos para abordar el caso colombiano, tanto en el ámbito norteamericano como europeo. Esto lo advierte Jane M. Rausch (2014a), con una mirada autocrítica, sobre las tendencias de los colombianistas norteamericanos en Estados Unidos. En su reciente trabajo, "Colombia’s Neutrality during 1914-1918: An Overlooked Dimension of World War", Rausch (2014b) señala además, que en 1915 la mirada de Alvin Martin (1967 [1925]) no reseñaba, que a pesar del papel

16 El Congreso Internacional contó con el respaldo institucional de la Universidad Nacional de Colombia, Universidad Autónoma de Colombia, Academia Colombiana de Historia, Biblioteca Nacional de Colombia, Asociación Colombiana de Historiadores y la Universidade Federal de Integracao Latino Americana. Fue celebrado en Bogotá entre el 11 y 15 de agosto de 2014. 
periférico de los latinoamericanos, estos sufrieron consecuencias notables del conflicto, aun con aquellos que asumieron una línea de neutralidad, como es el caso colombiano que le inspira.

Autores reconocidos como David Bushnell (1993); Marco Palacios (2006) y Marco Palacios y Frank Safford (2002); tienen ligeras referencias sobre el tema en sus trabajos. En general el tratamiento en cualquier texto es más de carácter informativo o textual. En la historiografía colombiana priman los antecedentes de la Guerra de los Mil Días y la pérdida del Istmo de Panamá, incluso la construcción del Canal de Panamá, además del impacto conocido como la Danza de los Millones, y un poco la Gran Depresión de 1929. Pero, en especial, ha interesado más la historia política de los diferentes gobiernos de comienzo de siglo XX (ver Ramírez, 2011b), sin análisis y relación respecto del ámbito nacional e internacional, y en el mejor de los casos, lo que se evidencia es cierta historia diplomática y militar a grandes rasgos como el texto Neutralidad y orden: política exterior y militar en Colombia 1886-1918 de Ricardo Esquivel Triana (2010) ${ }^{17}$.

Sin embargo, a juzgar por el reciente estudio de Rausch (2014b, 113), el papel que cumplió Colombia con su política de neutralidad fue mínimo, mientras su impacto fue sustancial. En realidad lo que inspira esta mirada es que hay que analizar el impacto de la IGM en Colombia, no limitándolos a los cuatro años del conflicto, sino a los efectos positivos y negativos que se desencadenaron posteriormente. En tal sentido, Rausch (2014c) publicó el texto Colombia and World War I: The Experience of a Neutral Latin American Nation during the Great War and Aftermath, 1914-1921; con el cual ofrece un balance crítico de las diversas pero escasas fuentes de información sobre el tema, donde también atiende asuntos propios de las relaciones diplomáticas, y el papel de la política de neutralidad asumido por Colombia durante y después de la guerra. Una de sus conclusiones es que, durante el periodo de estudio (1914-1921), lo más importante es que en

17 Para una mejor comprensión sobre la historiografía colombiana reciente ver: Ramírez (2008a; 2011a; 2011b), Ramírez y Ospina (2011, pp. 305-329), Gómez y Ramírez (2014).
Colombia se desarrollaron las condiciones políticas, económicas y sociales que prepararon al país para la conocida Danza de los Millones. La ratificación del Tratado Thomson-Urrutia en 1921 -relacionado con la cesión de Panana- fue el punto de inicio de la llegada al país de los 25 millones de dólares acordados con los estadounidenses como reparación por la pérdida de Panamá. Sin duda, otros textos, como los de Gerardo Molina (1974) y Raimundo Rivas (1961), ofrecen algunos datos y comprensiones sin mayor profundidad; aunque Antonio Rodríguez (1985) brinda, de modo sucinto y empírico, una contextualización histórica apropiada sobre la perspectiva de los efectos de la Gran Guerra en el país.

\section{Reflexiones finales}

Hasta aquí una mirada panorámica de la historiografía occidental y latinoamericana con énfasis en los casos de Argentina, México y Colombia. En realidad no es suficiente señalar sus vacíos y tendencias, los cuales siempre existirán; es necesario también reflexionar sobre el fenómeno en cuestión. En tal sentido este texto finaliza con las siguientes propuestas.

La literatura europea sobre la IGM hace y reitera la importancia de los estudios comparados y grandes posibilidades de análisis. Ya se sabe también que en Europa hay grandes limitaciones para cumplir tales programas, por razones lingüísticas, culturales y presupuestales. En el contexto latinoamericano si bien se revisaron algunos casos, son pocos los trabajos desde la perspectiva comparada, a excepción del texto de Albert y Henderson (1988). Es válido advertir que por la importancia económica y de intercambio comercial, geopolítico y militar de Brasil, Argentina y Chile, son los países que despiertan cierta atención para los historiadores anglosajones. E incluso de autores latinoamericanos que analizan las relaciones entre los países de la región, como Rimoldi (1994), quien estudia la dinámica de la relación entre Brasil y Argentina durante la guerra. Es quizás por eso que en ciertas líneas de trabajo, como la historia diplomática o económica, es posible hacer esfuerzos de comparación entre los países de la región. 
América Latina no fue el espacio para las trincheras y batallas con centenares de muertes. Por eso, y de acuerdo con Phillip Dehne (2014, p. 162), América Latina no se inscribe en la tendencia propia de la Historia Militar que ha prevalecido en estudios sobre la IGM. En cambio, fue la guerra la que definió gran parte de la historia europea y americana del siglo XX. Sin ese conflicto, como lo advierte Herfried Münkler $(2013)^{18}$ el planeta no hubiera tenido II Guerra Mundial, tampoco hubiera surgido el nacionalsocialismo, el stanilismo y sería difícil contemplar la Revolución bolchevique. Adicionalmente, la Gran Guerra traería consecuencias de orden cultural, pero en especial de orden económico. Esta es una buena razón para reivindicar su estudio no solo en los cursos sobre Historia de América Latina, sino también en la Historia Nacional de cada país latinoamericano; sobre todo porque se desconoce su impacto real. Entre otras, estas son las razones:

- La fractura económico-cultural de los latinoamericanos con el Viejo Continente. Esa influencia cultural en términos económicos, comerciales y científicos se rompe de manera abrupta. Lo anterior contrae dos situaciones: la primera, señalada por Pierre Purseigle: "La Primera Guerra Mundial creó importantes transformaciones en los países considerados neutrales, pues además de ser testigos, se creó una mayor conexión porque hubo circulación de información, intelectuales, literatura, etcétera. Hacia otros lados, incluyendo los países de esta región" (García, 2014). La segunda es que las economías de las naciones latinoamericanas, al ser proveedoras de materias primas, estaban fuertemente ligadas a las europeas. $\mathrm{La}$ Gran Guerra tuvo un causal económico y por su dependencia los países de la región recibieron severos efectos en el sector financiero. Hay altos índices de inflación, los salarios se reducen y aumenta el desempleo y con ello las tensiones sociales. En ese escenario emerge Estados Unidos como un socio comercial muy

18 Münkler, H. Der Große Krieg: Die Welt 1914-1918, es profesor de Ciencias Políticas en la Universidad Humboldt de Berlín. importante para muchos países. No se puede decir que fue la ruptura del desarrollo, pero sí de nuevas estrategias.

- La línea de neutralidad de varios países del continente, manifiesta inicialmente, y que se debió en gran medida a su carácter de proveedor de materias primas. Esta línea no fue bien vista por la Gran Bretaña y posteriormente por Estados Unidos, pues de igual modo la neutralidad era vista como una posición favorable a los alemanes y celebrada por estos. Esa línea sirvió en cierto modo para que Estados Unidos ofreciera su intromisión directa o indirecta en los asuntos internos de los países latinoamericanos, al pretender impedir el comercio directo con Alemania, interés no ajeno a apropiarse del mismo (Kuntz, 2014). La influencia militar o hegemonía norteamericana en algunos países del Caribe y Centroamérica era una realidad a comienzos del siglo $\mathrm{XX}^{19}$.

Sin embargo, la neutralidad fue rompiéndose con la participación de Estados Unidos en la guerra, de tal modo que llegaron las declaraciones de guerra a Alemania de varios países como Bolivia, Panamá, Cuba y Uruguay. Brasil fue el único país que envió tropas al Viejo Continente, pero estas no combatieron. Al final del conflicto los países tomaron partido según sus relaciones económicas y diplomáticas. Según el historiador Stefan Rinke (2014), al fin "ocho países se unieron a los aliados declarando la guerra a las potencias centrales; cinco rompieron relaciones; siete se mantuvieron neutrales"20. Jane Rausch (2014b, p. 104) y Olivier Compagnon (2005), advierten que ese aspecto es raramente discutido en la historiografía latinoa-

19 En 1898 se da la guerra entre España y Estados Unidos, con la expulsión del primero de dos de sus colonias: Cuba y Puerto Rico. Estados Unidos reinvade a Cuba entre 1906-1909, luego entre 1917 y 1922. También a México en 1914 y 1916; Republica Dominicana es ocupada entre 1905 y 1909 y entre 1916 y 1924; Haití es ocupada entre 1915 y 1934; Nicaragua entre 1912 y 1933; y parte de Panamá fue ocupada con el proyecto del canal interoceánico entre 1903 y 1999 (cf. Kadir, 2005).

20 Stefan Rinke es profesor de Historia Latinoamericana en la Universidad Libre de Berlín (cf. Zúñiga, 2014). 
mericana. Hay que recordar que España, de igual modo, asumió una línea de neutralidad, posición que ha sido analizada de diferentes maneras ${ }^{21}$. Y, que Argentina, en cabeza de su presidente Hipólito Yrigoyen, lideró esta línea que hizo carrera en la diplomacia internacional ${ }^{22}$.

En cualquier caso, la imagen de Europa cambió en el continente; se optó por una negativa, que sirvió a los distintos movimientos que emergieron posteriormente; en un contexto donde surge una clase media urbana y obrera en varias de las principales ciudades latinoamericanas. No por otra razón se evidencia cierta reorientaron de intereses hacia lo autóctono y nacional en diversos países, y de allí la emergencia de movimientos que siguen vigentes como el de la mujer, el indígena o el de los trabajadores y el estudiantil, los cuales llegaron a tener como marco de referencia la experiencia bolchevique rusa. Lo que también se traduce como el origen de movimientos emancipatorios y cambios culturales representados en las nuevas clases sociales, los jóvenes, las mujeres y el concepto de modernidad. Por esto, es posible entender que hay una historiografía occidental sobre movimientos sociales y la emergencia de nuevos grupos sociales, que pareciera no tener relación con la IGM y los distintos fenómenos desatados posteriormente; pero sí con la historiografía marxista de corte social y británico, o recientemente con la denominada historia cultural.

Lo anterior se deriva de otro hecho histórico en el marco de la Gran Guerra: la Revolución bolchevi$q^{2} e^{23}$. Ésta fue bien vista por los círculos y movimientos obreros e intelectuales, que como sabemos

21 Ver un referente: Nuño Aguirre (1995).

22 Cf. Hertog, y Kruizinga $(2011,71)$.

23 El escritor inglés Richard Ned Lebow, lo señala como la "primera consecuencia estrategia" de la IGM. Es lo que origina el nacimiento al primer estado socialista del mundo, una experiencia inédita en la historia de la humanidad. Una revolución que no solo incendio a Europa en los años siguientes, sino al anteriormente denominado tercer mundo. Sin olvidar que "además del ruso, se destruyeron todos los imperios: el alemán, el austro húngaro y el imperio turco. Se abrió un siglo de crisis, guerras y revoluciones, que, de alguna manera, todavía no ha terminado". Cf. El País.com.co, "Primera Guerra Mundial marcó un siglo de luchas que no terminan", junio tendrá su ambientación con la influencia de la historiografía social británica y el marxismo ortodoxo en el medio universitario a finales del siglo XX. Lo cierto es que muy poco se ha investigado sobre el impacto de la Revolución bolchevique en los ámbitos nacionales en su debido marco temporal; si bien su influencia e inspiración se empezó a sentir, en principio, en el medio universitario, y luego se extendió al sector obrero y popular.

El impacto de la guerra se puede resumir del siguiente modo: creación de nuevos Estados y acuerdos basados en principios étnicos, auge de los nacionalismos y emergencia de dictaduras autoritarias (cf. López, 2014), planificación estatal de la economía (Plan Rathenau alemán y luego los soviets adoptarían su primer Plan Quinquenal en 1928), nacimiento de un pacifismo modesto, emanicipación femenina, movimientos universitarios, auge del movimiento obrero y sindicalista, y tecnologización de los conflictos bélicos. Todo ello a una escala global (cf. Jiménez, 2014; Zúñiga, 2014). Entonces, ¿qué argumentos se tienen para no incluirla o relacionarla con la historia de Colombia y latinoamericana?

\section{Referencias bibliográficas}

ABC-Clio. Explore. Connect. Understand. (s.f.). Recuperado de: http://www.abc-clio.com/ABC-CLIOCorporate/About.aspx

Agencia EFE (3 de julio de 2014). El Bundestag recuerda el comienzo de la Primera Guerra Mundial. Caracol Radio. Recuperado de: http://www.caracol. com.co/noticias/entretenimiento/el-bundestagrecuerda-el-comienzo-de-la-primera-guerra-mundial/20140703/nota/2303664.aspx

Aguirre de Cárcer, N. (ed.) (1995). La neutralidad de España durante la Primera Guerra Mundial (19141918). Madrid: Ministerio de Asuntos Exteriores.

Albert, B. y Henderson, P. (1988). South America and the First World War: The Impact of the War on Brazil, Argentina, Peru, and Chile. Cambridge: Cambridge UniversityPress.

29 de 2014, http://www.elpais.com.co/elpais/internacional/noticias/ primera-guerra-mundial-marco-siglo-luchas-termina 
Babelia (4 de julio de 2014). 20 artículos para entender la Primera Guerra Mundial. El País. Recuperado de: http://cultura.elpais.com/cultura/2014/06/04/babelia/1401871263_984726.html

Bagú, S. (1996). Perspectiva de la historiografía latinoamericana. Boletín Americanista 36(46), 55-65.

Betancourt, A. (2008). Policromías de una región: procesos históricos y construcción del pasado local en el Eje Cafetero. Pereira: Red de Universidades Públicas del Eje Cafetero, Universidad Autónoma de San Luis Potosí, Coordinación de Ciencias Sociales y Humanas.

Bonilla, H. y Rabanal, A. (1979). La hacienda San Nicolás (Supe) y la Primera Guerra Mundial. Economía 2(3), 3-47.

Braybon, G. (ed.). (2003). Evidence, History, and the Great War: Historians and the Impact of 1914-18. Nueva York: Berghahn Books.

Bushnell, D. (1993). The Making of Modern Colombia: A Nation in Spite of Itself. Berkeley: University of California Press.

Compagnon, O. (2005). 1914-1918: The Death Throes of Civilization. The Elites of Latin-America Face. The Great War. En: J. Macleod y P. Purseigle (eds.). Uncovered Fields: Perspectives in First World War Studies. Leidin: Brill Academic Publishers.

Consejo Nacional para la Cultura y las Artes, México (Conaculta) (2014). Comunicado No. 1068/2014. Recuperado de: http://www.conaculta.gob.mx/detalle-nota/?id=34649\#.U7_YLvl5O-1

Couyoumdjian, J.R. (1986). Chile y Gran Bretaña: durante la Primera Guerra Mundial y la postguerra, 19141921. Santiago: Editorial Andrés Bello, Ediciones Universidad Católica de Chile.

Czamanski, D. y Folmer, H. (2011). Introduction: some new methods in regional science. The Annals of Regional Science, 47, 493-497. Recuperado de: http://www. springerlink.com/content/f52311g51wq5822m/fulltext.pdf

Dehne, P. (2014). How important was Latin America to the First World War? Iberoamericana, 53, 151-164.

D’haen, T.; Giles, P.; Kadir, D. y Zamora, L.P. (eds.) (2005). How Far Is America from Here? Ámsterdam: Editions Rodopi B. V.

Demografía en Argentina. (s.f.). Recuperado de: http://es.wikipedia.org/wiki/ Demograf\%C3\%ADa_de_Argentina
De Monserrat Llairó, M. y Siepe, R. (2005). Hipólito Yrigoyen, la neutralidad argentina y la Sociedad de las Naciones 1918-1920. Recuperado de: http://www. educar-argentina.com.ar/JUL2005/educ96.htm\#. U9ec6Pl5O-0

Den Hertog, J. y Kruizinga, S. (eds.) (2011). Caught in the Middle: Neutrals, Neutrality, and the First World War. Ámsterdam: Aksant Academic Publinshers.

Durán, E. (1981). El petróleo mexicano en la Primera Guerra Mundial. Cuadernos sobre prospectiva energética No. 12.México: El Colegio de México.

Durán, E. (1985). Guerra y revolución. Las grandes potencias y México, 1914-1918. México: El Colegio de México.

Esquivel T., R. (2010). Neutralidad y orden: Política exterior y militar en Colombia, 1886-1918. Bogotá: Pontificia Universidad Javeriana.

Estado Mayor General de Chile (2008). Historia del Ejército de Chile: La Primera Guerra Mundial y su influencia en el ejército, 1914-1940. Vol. 8. Chile: Estado Mayor General del Ejército..

García E., V. (27 de julio de 2014). La historia olvida participación de AL en la Primera Guerra Mundial: experto. Crónica.com.mx. Recuperado de: http:// www.cronica.com.mx/notas/2014/841707.html

Glinkin, A.N. (1984). El latinoamericanismo contra el panamericanismo: desde Simón Bolívar hasta nuestros días. Moscú: Editorial Progreso.

Gómez, E. y Ramírez, R. (2014). Historiografía de la regionalización en Colombia: una mirada institucional e interdisciplinar, 1902-1987. HiSTOReLo. Revista de Historia Regional y Local 6(11), 13-67.

Heather, J. (2014). La I Guerra Mundial: ¿fue realmente global y la primera? BBCMundo.com. Recuperado de: http://www.ecuavisa.com/articulo/bbc/internacional/69521-i-guerra-mundial-fue-realmente-global-primera.

Horne, J. (ed.) (2012). A Companion to World War I. EE.UU./Reino Unido: Blackwell Publishing Ltd.

Instituto Ibero-Americano (Berlín), Institute of Latin American Studies (Hamburgo) y Editorial Iberoamericana/Vervuert (Frankfurt am Main/ Madrid). (2014). Iberoamericana, 14, 53. Recuperado de: http://journals.iai.spk-berlin.de/index.php/ iberoamericana/issue/view/6.

Ipec - Provincia de Santa Fe (s.f.). A 100 años de la Primera Guerra Mundial Homenaje a las vícti- 
mas. Recuperado de: http://www.santafe.gov.ar/ index.php/web/content/download/200408/971539/ file/1\%C2\%BA\%20Guerra\%20Mundial\%20definitivo.pdf.

Jiménez P., A. (29 de julio de 2014). La Primera Guerra Mundial marcó un antes y un después en la humanidad. Los Tiempos. Recuperado de: http:// www.lostiempos.com/diario/actualidad/internacional/20140629/la-primera-guerra-mundial-marcoun-antes-y-un-despues-en-la_264816_579998.html.

Kadir, D. (2005). Defending America against its Devotees. En: T. D'haen; P. Giles, D. Kadir y L. Parkinzon (eds.). How Far Is America from Here? (pp. 13-34). Ámsterdam: Editions Rodopi B. V.

Katz, F. (1984). La guerra secreta en México. Tomo 2. La Revolución Méxicana y la tormenta de la Primera Guerra Mundial. México: Ediciones Era.

Kuntz F., S. (2014). El impacto de la Primera Guerra Mundial sobre el comercio exterior mexicano. Iberoamericana, 53, 117-137.

Lascano, D. (2002). Grafvon Spee: de China a Malvinas; la Primera Guerra Mundial en aguas de Chile y Argentina. Santiago de Chile: Ediciones Pictoria

López V., A. (28 de julio de 2014). Sarajevo 1914: El pistoletazo nacionalista que incendió Europa. ABC.es. Recuperado de: http://www.abc.es/internacional/20140628/abci-centenario-guerra-mundial-201406272043.html

Madueño, V. (1981). La Primera Guerra Mundial y el desarrollo industrial del Perú. Estudiosandinos 9(17/18), 41-53.

Martin, P.A. (1925). Latin America and the War. Baltimore: Johns Hopkins.

Meyer, L. (3 de julio de 2014). Primera Guerra Mundial facilitó Revolución mexicana. Reforma. Recuperado de: http://noticias.terra.com.mx/mexico/primeraguerra-mundial-facilito-revolucion-mexicana-mey er,fc13e2cc63cf6410VgnVCM3000009af154d0R CRD.html

Molina, G. (1974). Las ideas liberales en Colombia 19151934. Bogotá: Tercer Mundo Editores.

Monserrat, M. y Siepe R. [2005]. "Hipólito Yrigoyen, la neutralidad argentina y la Sociedad de las Naciones 1918-1920", http://www.educar-argentina.com.ar/ JUL2005/educ96.htm\#.U9ec6Pl5O-0

Münkler, H. (2003). Der Große Krieg: Die Welt 1914-1918. Berlin: Rowohlt.
Otero, H. (2011). Emigración, movilización militar y cultura de guerra. Los franceses de la Argentina durante la Gran Guerra. Amnis, 10. Recuperado de: http:// amnis.revues.org/1137. DOI: 10.4000/amnis.1137

Palacios, M. (2006). Between Legitimacy and Violence: A History of Colombia, 1875-2002. Durham: Duke University Press.

Palacios, M. y Safford F. 2002. Colombia: país fragmentado, sociedad dividida: su historia. Bogotá: Grupo Editorial Norma.

Parra, Y. de la (1986). La Primera Guerra Mundial y la prensa mexicana. Estudios de historia moderna y contemporánea de México, 10, 155-176.

Pinto V., J. (1996). Crisis salitrera y subversión social: los trabajadores pampinos en la pos-primera Guerra Mundial (1917-1921). Boletín del Instituto de Historia Argentina y Americana Dr. Emilio Ravignani, 14, 61-92.

Presidencia de la República de México (2013). Aniversario del inicio de la Revolución mexicana. Recuperado de: http://www.presidencia.gob.mx/ aniversario-del-inicio-de-la-revolucion-mexicana/

Primera Guerra Mundial marcó un siglo de luchas que no terminan. (2014). Recuperado de: http://www. elpais.com.co/elpais/internacional/noticias/primeraguerra-mundial-marco-siglo-luchas-termina

Purseigle, P. y Macleod, J. (2005). Introduction: Perspective in First World War Studies. En: J. Macleod y P. (eds.). Uncovered Fields: Perspectives in First World War Studies (pp. 1-23). Leidin: Brill Academic Publishers.

Ramírez, R. (2008a). Breve historia de la historiografía colombiana. En: R. Ramírezy A. Betancourt (comp.). Ensayos sobre historia y cultura en América Latina (pp. 137-156). Medellín: Universidad Nacional de Colombia.

Ramírez, R. (2008b). El historicismo: profesionalización e ideologización de la historia. En: E. Domínguez (comp.). Historia de las ideologías políticas, Proyecto Ágora (pp. 425-437). Medellín: Canal U-Fondo Editorial Universidad EAFIT.

Ramírez, R. (2011a). Historia regional en el marco de la historia cultural. En: M. Hering y A.C. Pérez (eds.). Estudios culturales en Colombia. Categorías y Debates (pp. 365-375). Bogotá: Universidad Nacional de Colombia, Universidad de los Andes, Universidad Pontifica Bolivariana. 
Ramírez, R. (2011b). Tendencias de la historia regional en Colombia. Problemas y perspectivas recientes. HiSTOReLo. Revista de Historia Regional y Local 3(5), 147-168. Recuperado de: http://www.revistas. unal.edu.co/index.php/historelo/article/view/20653/ pdf_41

Ramírez, R. y Ospina, M. (2011). Historiografiar los héroes y sus localidades. El caso de la Academia Antioqueña de Historia y la problemática de la independencia. En: Y.A. Chicangana y F.A. Ortega. 200 años de Independencias. Las culturas políticas y sus legados (pp. 305-329). Medellín: Universidad Nacional de Colombia.

Rausch, J. M. (2014a). ... amplíen sus intereses más allá de su propia región y de otros países, además de Colombia, con el fin de poder hacer comparaciones válidas y hacer un caso más claro del contexto de Colombia en el hemisferio occidental. HiSTOReLo 6(11), 349365. Entrevista realizada por Renzo Ramírez Bacca. Recuperado de: http://www.revistas.unal.edu.co/ index.php/historelo/article/view/42094/pdf_53

Rausch, J. M. (2014b). Colombia's Neutrality during 19141918: An Overlooked Dimension of World War I. Iberoamericana, 53, 103-115.

Rausch, J. M. (2014c). Colombia and World War I: The Experience of a Neutral Latin American Nation during the Great War and Aftermath, 1914-1921. Maryland: Lexington Books. Recuperado de: http://books.google.com.co/books

Renouvin, P. (1999). La crisis europea y la Primera Guerra Mundial. Madrid: Ediciones Akal.

República Argentina, Conaculta, Comunicado No. 1068/2014, http://www.conaculta.gob.mx/detallenota/?id=34649\#.U7_YLvl5O-1

Rimoldi, M.J. (1994). Argentina-Brasil: dinámica de relación en la coyuntura 1914-1918. En: Temas de Historia Argentina 11. Estudios/Investigaciones series no. 16. Argentina: Universidad Nacional de La Plata, Facultad de Humanidades y Ciencias de la Educación.

Rinke, S. (2014). América Latina y la Primera Guerra Mundial, nuevos estudios, nuevas interpretaciones. Iberoamericana, 53, 87-89.

Rivas, R. (1961). Historia diplomática de Colombia 18101934. Bogotá: Imprenta Nacional.
Rodríguez, A. (1985). Efectos de la Primera Guerra Mundial. En: R. Arango (dir.). Historia de Colombia. Nuestra Historia (pp. 73-88). Bogotá: Editorial La Oveja Negra.

Rudavičius, V.(16demayo de2014). Jóvenes británicossaben poco de guerras mundiales. Televisa Londres. Recuperado de: http://noticieros.televisa.com/mundo/1405/ jovenes-britanicos-saben-poco-guerras-mundiales/

Sánchez, L.C. (2014). Impacto latino en la Guerra, conmemoran centenario. Excelsior. Especiales. Recuperado de: http://www.excelsior.com.mx/ expresiones/2014/06/25/967142

Sánchez, R.; Bellver, J.M.; Fresneda, C.; Colás, X.; Melguizo, S.; Hurtado, L.M.; Ramírez, M. y Gallego, J. (2014). Primera Guerra Mundial. 100 años 19142014. La mirada hoy. Historia en las Escuelas. ElMundo.es. Recuperado de: http://www.elmundo. es/especiales/primera-guerra-mundial/mirada-hoy/ escuela/alemania.html

Santanu, D. (ed.) (2011). Race, empire and First World War writing. Cambridge, Nueva York: Cambridge University Press.

Servicio de Educación para el Arte (SEPA). (s.f.). Sábado de Gloria. Historia de los argentinos... 1914: Población - Neutralidad argentina... Recuperado de: http:// www.sepaargentina.com.ar/index.php?option=com_ content $\&$ view $=$ article $\& i d=954 \% 3$ Asabado- de-gloria-historia-de-los-argentinos $\&$ catid $=88 \% 3$ Ahisto ria-argentina\&Itemid $=69$ \&limitstart $=20$

Siepe, R. (1992). Yrigoyen, la Primera Guerra Mundial y las relaciones económicas. Buenos Aires: Centro Editor de América Latina.

Tarruella, R. (2014). 1914. Argentina y la Primera Guerra Mundial. Buenos Aires: Aguilar.

Tato, M. I. (2008). La disputa por la argentinidad: rupturistas y neutralistas durante la Primera Guerra Mundial. Temas de historia argentina y americana. 13, 227-250.

Tato, M. I. (2011). El llamado de la patria: británicos e italianos residentes en la Argentina frente a la Primera Guerra Mundial. Estudios Migratorios Latinoamericanos 25(71), 273-292.

Tato, M.I. (2012). Contra la corriente: los intelectuales germanófilos argentinos frente a la Primera Guerra Mundial. JahrbuchfurGeschichteLateinamerikas, 49, 205-223. 
Universidad Pedagógica Nacional

Facultad de Humanidades

Tato, M. I. (2014). La Gran Guerra en la historiografía argentina. Balance y perspectivas de investigación. Iberoamericana, 53, 91-101.

Usi, E. (3 de julio de 2014). Latinoamérica y la Primera Guerra Mundial. $D W$. Recuperado de: http://www. dw.de/latinoam\%C3\%A9rica-y-la-primera-guerramundial/a-17754280

Velásquez, R. (2005). Venezuela y la Primera Guerra Mundial (1914-1918). Boletín de la Academia Nacional de la Historia de Venezuela, 350.

Vivas G., F. (1981). Venezuela y la Primera Guerra Mundial: de la neutralidad al compromiso. Octubre /1914 - Marzo/ 1919. Revista de la Facultad de Ciencias Jurídicas y Políticas, 61, 113-133.

Weinmann, R. (1994). Argentina en la Primera Guerra Mundial: neutralidad, transición política y continuismo económico. Buenos Aires. Biblos-Fundación Simón Rodríguez.

Womack Jr., J. (1987). La economía de México durante la Revolución, 1910-1920: historiografía y análisis. Argumentos, 1, 9-42.

Zúñiga, D. (29 de mayo de 2014). Guerra y Latinoamérica: una fractura cultural. DW. Recuperado de: http:// www.dw.de/guerra-y-latinoam\%C3\%A9rica-unafractura-cultural/a-17670793 